\title{
A Study on the Effectiveness of Manual Mulligan Traction Compared to Intermittent Electrical Traction in Patients with Cervical Spondylosis
}

\author{
Arul Pragassame S. ${ }^{1 *}$, Mohandas Kurup V. K. ${ }^{2}$ and Sivashanmugam V. ${ }^{3}$ \\ 'Assistant Professor, Department of PM\&R, RMMC\&H, Annamalai University, Annamalai Nagar - 608002, \\ Tamilnadu, India; arulphysio77@gmail.com \\ 2Professor \& Head of the Department, Department of PM\&R, RMMC\&H, Annamalai University, \\ Annamalai Nagar - 608002, Tamilnadu, India \\ 3Department of PM\&R, RMMC\&H, Annamalai University, Annamalai Nagar - 608002, Tamilnadu, India
}

\begin{abstract}
Cervical traction is a variety of practicing methods depending on the pathology being treated. The established effectiveness in cervical spondylosis of these different methods makes it a useful tool for physiotherapy practitioners. However, its role in cervical spondylosis is uncertain. Comparing manual Mulligan traction and intermittent electrical traction would provide information of great importance to the scientific community on the use of cervical traction in patients with cervical spondylosis. The purpose of the present study is to find out and compare the effectiveness of manual Mulligan traction versus intermittent electrical traction on pain, range of motion (ROM) and functional disability in patients with cervical spondylosis. A total of 30 subjects with cervical spondylosis were selected and screened for inclusion and exclusion criteria. Initially, the pain intensity was evaluated using the Numerical Pain Rating scale (NPRS). The active ROM of cervical extension and cervical Lt/Rt rotation was measured with inch tape and functional disability by using the scale of the neck disability index (NDI). Participants were then allocated into two A\&B groups. Group A (N=15) was given manual Mulligan traction with interferential therapy (IFT) and isometric neck exercise, and group $\mathrm{B}(\mathrm{N}=15)$ was given intermittent electrical traction with IFT and isometric neck exercise. Group A showed significant improvements in NPRS ( $\mathrm{Z}=9.77, \mathrm{P}=0.002)$, NDI $(\mathrm{t}=2.76, \mathrm{P}=0.010), \mathrm{ROM}$ of cervical extension $(\mathrm{t}=7.26, \mathrm{P}=0.026)$ and cervical left rotation $(\mathrm{t}=2.31, \mathrm{P}=0.029)$ when compared to group $\mathrm{B}$, but the level of improvement in cervical right rotation was insignificant $(\mathrm{t}=1.89, \mathrm{P}=0.07)$. Hence it is concluded that manual Mulligan traction and intermittent electrical traction are effective in reducing pain, improving cervical ROM and functional performance in cervical spondylosis. However the subject who received the manual Mulligan traction with IFT and isometric neck exercise showed better improvement in reducing pain, improving cervical ROM and functional performance than subject who received the intermittent electrical traction.
\end{abstract}

Keywords: Cervical Spondylosis, Interferential Therapy, Intermittent Electrical Traction, Manual Mulligan Traction, Neck Disability Index

\section{Introduction}

The cervical spine has greater mobility and poor anatomical support than the lumbar and thoracic spine, leading to early pathological changes that may lead to discomfort. Neck pain is the second major cause of moment after low back pain. Neck pain and its associated disability are a major socioeconomic burden for society. It

${ }^{*}$ Author for correspondence 
is more common in women than men at around 35years of age and above ${ }^{1}$.

Cervical Spondylosis (CS) is a condition caused by abnormal wear and tear of the cervical spine soft tissue, disks or vertebrae. Wear and tear results in a gradual reduction of disc space, loss of the normal square shaped bone and development of bone edges (bone spurs). Often, spondylosis specifically affects the facet joints in the spine ${ }^{2}$. It is also known as arthritis of the neck, cervical osteoarthritis or degenerative osteoarthritis. The average annual incidence rate of cervical conditions is 83 per 100,000 with increased prevalence in the fifth decade of life $(203 \text { per } 100,000)^{3}$.

The etiology of cervical spondylosis is multifactorial and poorly understood. The common factor includes poor posture, depression, anxiety, aging, reduction in the disk's ability to hold or carry additional axial loads along the cervical spine, acute cervical injury and occupational or sports activity which leads to altered joint mechanics resulting cervical spondylosis ${ }^{4}$. Its signs and symptoms include pain, limitation of neck movement; headache, tenderness, paresthesia or muscle weakness, or a combination of these is the most commonly reported symptoms ${ }^{5}$.

Physiotherapy treatment should be taken for individual patients, but includes supervised isometric exercises, Electrotherapy, proprioceptive, re-education, manual therapy, patient education, posture corrections and ergonomics. Traction is one of the commonly used treatments for Cervical Spondylosis. Traction can be given in various forms such as manual traction, motorized traction, suspension and bed traction. The most commonly used of these is manual and electrical traction ${ }^{6}$.

Manual Mulligan Traction (MMT) interventions are an appropriate treatment strategy for patients with neck pain ${ }^{7}$. The goal of manual traction is to reduce pain and to improve the function of the cervical spine, usually for 15-60 seconds. The therapeutic effect of manual Mulligan traction helps to stretch the posterior structure and opens the intervertebral foramen, helps with nutrition the facet joint and the disc, correct the positional faults between affected facets and correct the biomechanics of the joint ${ }^{8}$.

Intermittent Electrical Traction (IET) alternately applies and releases the traction forces at short intervals. The period of force application usually refers to the hold period $(20 \mathrm{Sec})$ and the release period is the rest period $\left(10 \mathrm{sec}\right.$.). In cervical traction, $1 / 8^{\text {th }}$ of the total body weight was applied ${ }^{9}$. The therapeutic effect of electrical traction is based on sustained and reflex mechanism ${ }^{10}$. Spinal elongation through increased intervertebral space and relaxation of the spinal muscles is assumed to have the most important role in the proposed mechanism by which IET could be effective ${ }^{11}$.

It is not known which of these two interventions (MMT and IET) are the most effective form of intervention. However, there are few literature studies comparing the effects of manual Mulligan traction with electrical traction. Therefore, the purpose of our study is to compare the effectiveness of manual mulligan traction with intermittent electrical traction.

\section{Materials and Methods}

\subsection{Participants}

Fourty-eight patients with Cervical spondylosis and who attended the PMR Outpatient Department, RMMC\&H, Annamalai University, Tamil Nadu, India during the months of September, October and November 2018 were selected using the Convenient sampling method. Out of which 18 were excluded (not meeting selection criteria $n=9$, declined to participate $n=4$, other reasons $n=5$ ), the remaining 30 patients were chosen as study samples.

The inclusion criteria for the study were: 1 . Age group between 35-60 years, 2. Both males and females, and 3. Neck disability index score of 10 or higher. The exclusion criteria were: 1 . History of previous cervical surgery, 2. Cervical trauma with fracture and dislocation, 3. Osteoporosis, 4. Rheumatoid arthritis, and 5. Acute cervical radiculopathy.

\subsection{Study Procedure}

The study was approved by the Departmental Research Committeebefore the study procedure (PMR/DRC-6/2018). After screening for selection criteria, patients were informed about the purpose, study method and informed consent obtained for participation individually. Demographic data were collected. Subjects were randomly allocated into two groups, i.e., Odd number were in Group A and Even number were in Group B. Group A ( $\mathrm{N}=15)$ patients received manual Mulligan traction with IFT and isometric neck exercise, and 
group B $(\mathrm{N}=15)$ received intermittent electrical traction with IFT and isometric neck exercise. Initially, the pain intensity was evaluated using the Numerical Pain Rating Scale (NPRS). The active range of cervical extension and cervical rotation $\mathrm{Rt} / \mathrm{Lt}$ was measured with inch tape and functional disability by using the scale of the neck disability index. Pre and post evaluation measures were compared and statistically analyzed. The above evaluation was performed on the first visit with the patient before the beginning of treatment and again on the last day of treatment at the end of the $7^{\text {th }}$ day, frequency was one session/day, and the patient allowed continuing their regular medication (analgesics) as prescribed by the physician.

\section{Outcome Measures}

\subsection{Primary Outcome Measures}

\subsubsection{Numerical Pain Rating Scale (NPRS) ${ }^{12}$}

The NPRS was found to be a reliable and effective outcome of pain measurement. The straight line was drawn from left to right on the evaluation sheet with two end points ' 0 ' and ' 10 '. The ' 0 ' end indicates no pain, whereas the ' 10 ' end indicates severe pain. Patients were asked to mark a point on the line corresponding to the amount of pain they experienced during the evaluation.

\subsubsection{Cervical Range of Motion ${ }^{13}$}

Tape Measurement

\subsubsection{Cervical Extension}

The mean cervical extension ROM measured by a range of tape measurements from 18.5 to $22.4 \mathrm{~cm}$. A tape measurement can be used to measure the distance between the tip of the chin and the Sternal notch. Be sure that the mouth of the subject remains closed during measurement the examiner measure at the end of the ROM.

\subsubsection{Cervical Rotation $\mathrm{Rt} / \mathrm{Lt}$}

The mean cervical rotation ROM measured to the left/ right with a tape measure range from 11.0 to $13.2 \mathrm{~cm}$. A tape measurement can be used to measure the distance between the tip of the chin and the acromial process the examiner measure at the end of the ROM.

\subsection{Secondary Outcome Measures}

\subsubsection{Neck Disability Index Scale (NDI $)^{14}$}

The Neck Disability Index (NDI) described by Vernon \& Mior is based on the Oswestry Low Back Pain Disability Index, and specifically measures activity limitations due to neck pain. The NDI has become a standard tool for measuring self-related disability due to neck pain and is used by clinicians and researchers alike. The NDI contains 10 items - 7 relating to activities of daily living, 2 relating to pain and 1 relating to concentration items is scored from $0-5$, and the total score is expressed as a percentage (total possible score, $100 \%$ ), with higher scores corresponding to greater disability.

\section{Scoring the NDI:}

$\begin{array}{ll}0-4 & =\text { No disability } \\ 5-14 & =\text { Mild disability } \\ 15-24 & =\text { Moderate disability } \\ 25-34 & =\text { Severe disability } \\ 35 \text { or ove } & =\text { Complete disability }\end{array}$

\section{Treatment Procedure}

The total treatment duration was 7 days, the frequency was one session/day. Both the groups received Interferential therapy (15 minutes) and isometric neck exercises (Neck flexors, extensors, side flexors and rotators) were taught to patients.

\section{Group-A}

Manual Mulligan Traction ${ }^{8}$

The therapist performed manual cervical traction using a 2-inch belt. The therapist supports the patient's head while applying a gentle, stable and controlled distraction force.

Patient position:

Supine lying (with chin tucked in/retracted).

Therapist position:

Standing towards the head end of the patient.

Belt placement:

The belt should be over the upper back and should pass through the radial groove of the therapist's upper arm. Index and middle finger should be kept inside the belt.

Hand placement:

The desired cervical level should be placed in the space between the index and middle finger. 


\section{Mobilization:}

After hooking the desired level therapist simply lean back (lunges) to apply vertical pull (Figure 1-3).

\section{Group-B}

Intermittent Electric Traction ${ }^{9,11}$

Tension is applied for a "hold" period at a prescribed load (weight) for a prescribed amount of time (seconds) followed by rest period at a lower load (weight) for a prescribed amount of time (seconds) (Figure 4).

Patient position:

Supine lying position, Mechanical intermittent cervical traction uses a head harness attached at the end of a table to a mechanical device. The device can pull off intermittent traction.

\section{Dosage:}

$1 / 8^{\text {th }}$ of total body weight.

30 seconds holds with a 10 second rest applied for 10 minutes.

\section{Data Analysis and Results}

The improvement in pre and post measurement is studied by Wilcoxon signed rank test for NDI and Paired sample " $t$ " test for other outcome measures. The comparison of improvement between groups is analyzed by Mann Whitney ' $u$ ' test for NDI and Independent sample " $\mathrm{t}$ " test for another outcome variable. The level of significance $\alpha=0.05$. The data were presented in tabular form. The entire statistical procedure is carried out by statistical packages of social science (SPSS-21).

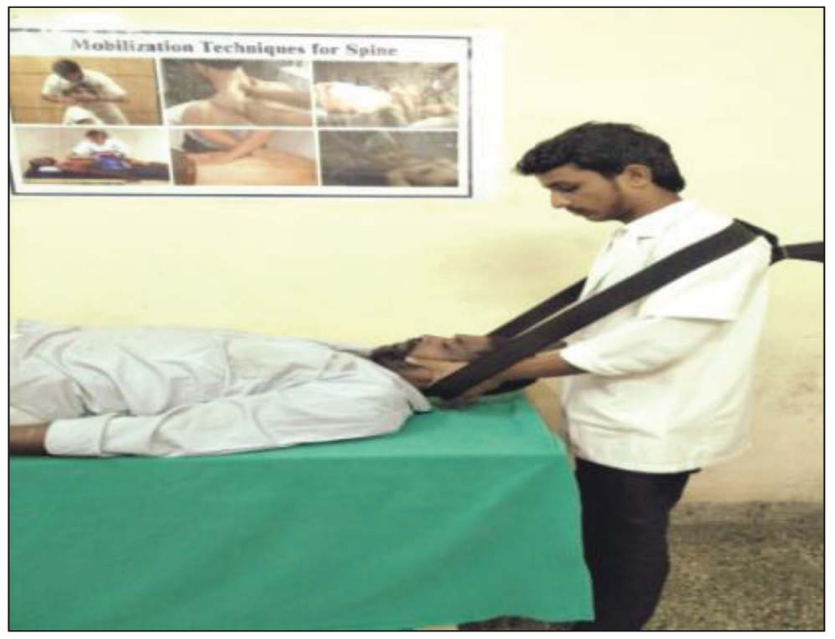

Figure 1. Starting Position.

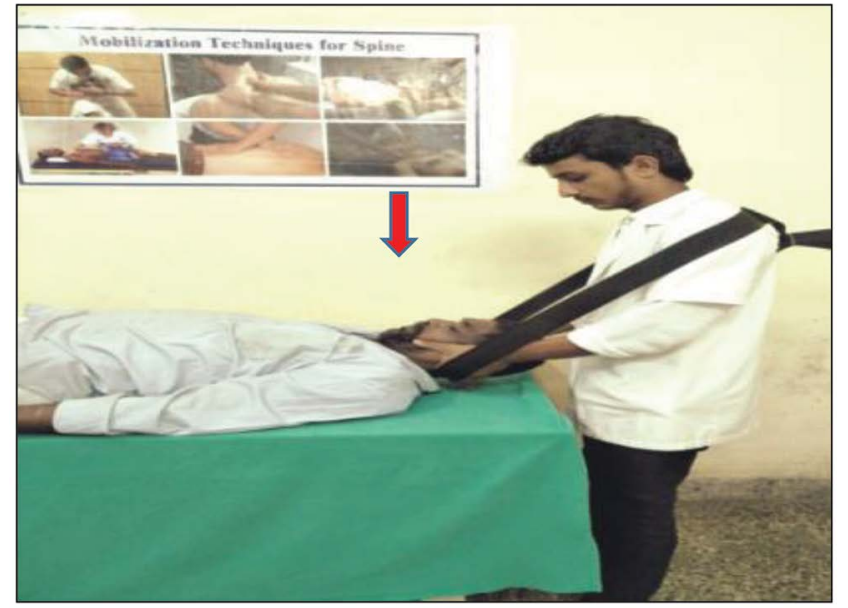

Figure 2. Chin tucked.

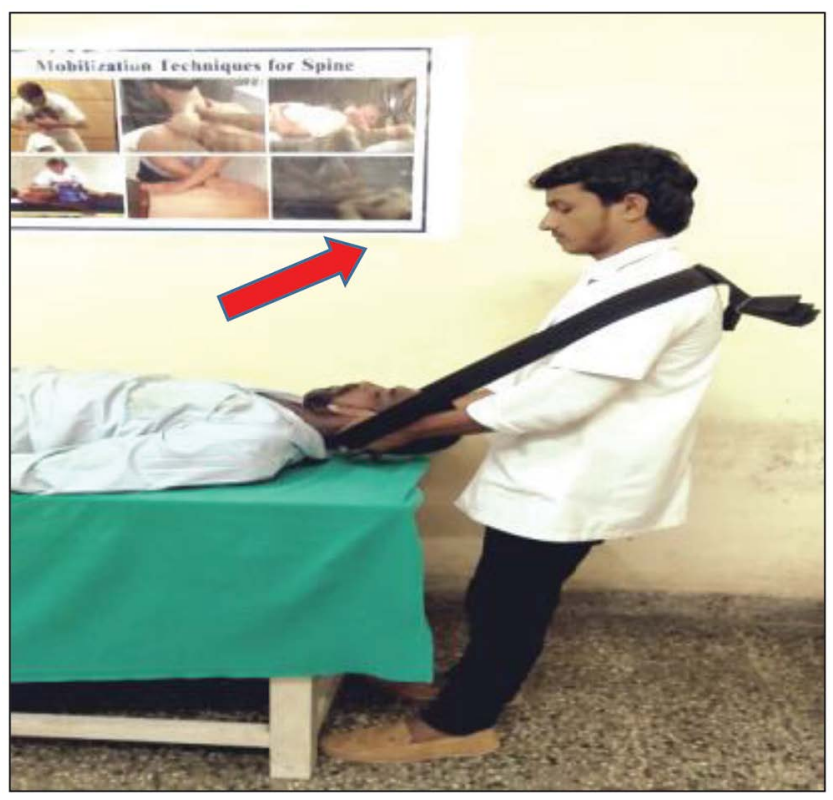

Figure 3. Vertical traction.

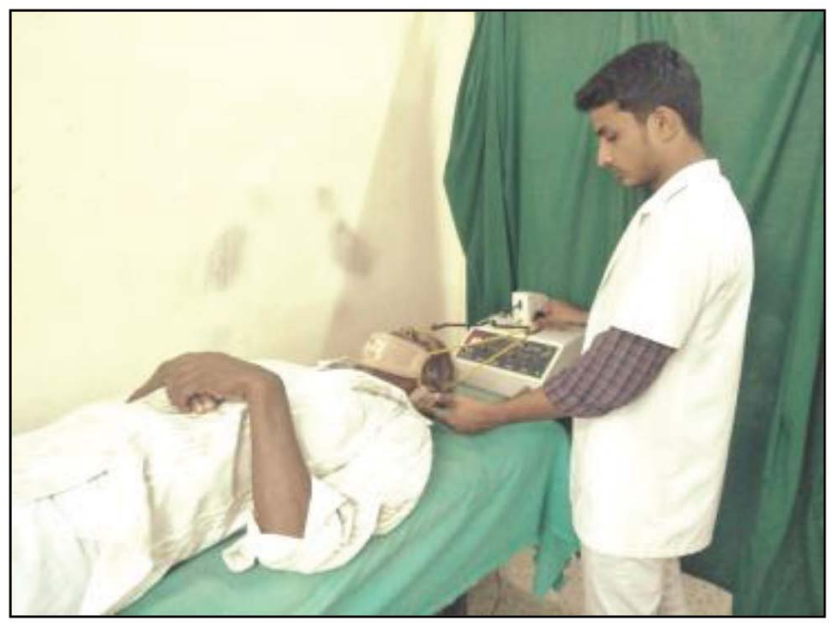

Figure 4. Intermittent Electrical Traction. 
The mean age of the study population was 44.27 years with the corresponding standard deviation of 8.46 in Group A. The other baseline characters of group A and group B are presented in (Table 1).

Table 1. Baseline characteristics of the group A and $\mathrm{B}$

\begin{tabular}{|c|c|c|c|c|c|}
\hline Characteristics & \multicolumn{2}{|c|}{ Group A } & \multicolumn{2}{|c|}{ Group B } & P Value \\
\hline Age & $\begin{array}{c}44.27 \\
\text { (Mean) }\end{array}$ & $\begin{array}{l}8.46 \\
(\mathrm{SD}) \\
\end{array}$ & $\begin{array}{c}43.13 \\
\text { (Mean) }\end{array}$ & $\begin{array}{l}7.39 \\
(\mathrm{SD}) \\
\end{array}$ & 0.10 \\
\hline Sex & $\mathbf{N}$ & $\%$ & $\mathbf{N}$ & $\%$ & \multirow{3}{*}{0.12} \\
\hline Male & 5 & 33.3 & 5 & 33.3 & \\
\hline Female & 10 & 66.7 & 10 & 66.7 & \\
\hline Occupation & $\mathbf{N}$ & $\%$ & $\mathbf{N}$ & $\%$ & \multirow{6}{*}{0.14} \\
\hline Housewife & 3 & 20 & 6 & 40 & \\
\hline Teacher & 1 & 6.7 & 2 & 13.3 & \\
\hline Tailor & 1 & 6.7 & 1 & 6.7 & \\
\hline Manual worker & 10 & 66.7 & 5 & 33.3 & \\
\hline Nurse & - & - & 1 & 6.7 & \\
\hline $\begin{array}{l}\text { Duration of } \\
\text { condition, } \\
\text { months }\end{array}$ & $\mathbf{N}$ & $\%$ & $\mathbf{N}$ & $\%$ & \multirow{5}{*}{0.15} \\
\hline $1-3$ & 10 & 66.7 & 8 & 53.3 & \\
\hline $3-6$ & - & - & 2 & 13.3 & \\
\hline $6-9$ & 1 & 6.7 & 2 & 13.3 & \\
\hline$>9$ & 4 & 26.7 & 3 & 20.0 & \\
\hline
\end{tabular}

N: Number; SD: Standard deviation; \%: Percentage.

The mean pre NPRS for group 'A' was $6.40 \pm 1.35$ and it was reduced after treatment to $3.47 \pm 0.83$. The reduction is statistically significant ( $\left(\mathrm{z} '=3.46,{ }^{\prime} \mathrm{p} '=0.001\right.$ ).

The mean pre NPRS for group 'B' was $5.47 \pm 1.12$ and the mean reduction after treatment was $3.67 \pm 1.05$. The reduction of NPRS is again statistically significant (' $\mathrm{z}$ ' $=$ 3.54 , ' $\mathrm{p}$ ' $=0.001$ ).

The mean difference of improvement in group ' $\mathrm{A}$ ' was $2.93 \pm 0.88$ and which is comparatively higher than group ' $\mathrm{B}$ ' $(\mathrm{m}=1.93 \pm 0.59)$. The difference is statistically significant ( $z$ ' $=9.77$, ' $p$ ' $=0.002$ ). Therefore, the reduction in NPRS (improvement) is significantly higher in group 'A' (Table 2).

The mean cervical extension ROM for group 'A' was 16.91 \pm 0.68 and is increased to $18.45 \pm 0.62$ after treatment. The difference in the improvement is statistically significant ( $\mathfrak{A}$ ' $=$ 10.75 , ' $\mathrm{p}$ ' $=0.001$ ). The mean pre cervical extension ROM for group 'B' was $16.91 \pm 1.23$ and after treatment it is increased
Table 2. NPRS comparison

\begin{tabular}{|l|c|c|c|c|c|c|}
\hline \multirow{2}{*}{ NPRS } & \multicolumn{2}{|c|}{ Group A } & \multicolumn{2}{c|}{ Group B } & \multicolumn{2}{c|}{$\begin{array}{c}\text { Independent } \\
\text { Sample }\end{array}$} \\
\cline { 2 - 6 } & Mean & S.D & Mean & S.D & 'Z' & 'P' \\
\hline Pre & 6.40 & 1.35 & 5.47 & 1.12 & \multirow{2}{*}{9.77} & 0.002 \\
\hline Post & 3.47 & 0.83 & 3.67 & 1.05 & & \\
\hline $\begin{array}{l}\text { Pre-post } \\
\text { Difference }\end{array}$ & 2.93 & 0.88 & 1.93 & 0.59 & & \\
\hline $\begin{array}{l}\text { Wilcoxon } \\
\text { Singed rank } \\
\text { Test 'z' }\end{array}$ & \multicolumn{2}{|c|}{3.46} & \multicolumn{2}{|c|}{3.54} & & \\
\cline { 1 - 4 } 'P' & \multicolumn{2}{|c|}{0.001} & \multicolumn{2}{|c|}{0.001} & \\
\hline
\end{tabular}

to $17.96 \pm 0.78$. The difference in improvement is again statistically significant $\left('{ }^{\prime} '=7.26,{ }^{\prime} \mathrm{p} '=0.001\right)$

Between group comparison, the mean improvement was comparatively higher in group A $(\mathrm{m}=1.53 \pm 0.55)$ than in group $\mathrm{B}(\mathrm{m}=1.05 \pm 0.56)$ and the difference is statistically significant ( $\left(\mathrm{t}\right.$ ' $=2.36,{ }^{\prime} \mathrm{p}$ ' $=0.026$ ) (Table 3 ).

The mean pre right cervical rotation for group 'A' was $14.09 \pm 1.58$ and is reduced to $13.12 \pm 0.98$ after treatment. The difference is statistically significant ( $\left(\mathfrak{t} '=4.99,{ }^{\prime} \mathrm{p} '=0.001\right.$ ). The mean pre right cervical rotation for group $\mathrm{B}$ was 13.23 \pm 0.98 and was reduced to $12.71 \pm 0.65$ after treatment. The difference is again statistically significant ( $(\mathfrak{t})=3.80,{ }^{\prime} \mathrm{p} '=0.002$ )

The comparison between group shows that, the mean improvement in group 'A' was comparatively higher ( $\mathrm{m}=$ $0.97 \pm 0.75)$ than group ' $\mathrm{B}$ ' $(\mathrm{m}=0.52 \pm 0.53)$ even though the difference is statistically insignificant $\left(' \mathfrak{t}=1.89,{ }^{\prime} \mathrm{p}\right.$ ' $\left.=0.07\right)$ (Table 4).

The mean pre-left cervical rotation for group 'A' was $14.11 \pm 1.54$, and after treatment the mean was reduced to $13.09 \pm 0.97$. The difference is statistically significant ( $' \mathrm{t}$ ' $=5.33$, ' $\mathrm{p}$ ' $=0.001$ ). The mean pre-left cervical rotation for group 'B' was $13.13 \pm 1.05$ and after treatment the mean was reduced to $12.59 \pm 0.92$. The comparison between group shows that the mean improvement was $1.01 \pm 0.73$ for group 'A' and $0.54 \pm 0.08$ for group 'B'. The difference is statistically significant. Therefore, left cervical rotation had a significantly higher improvement in group 'A' than in group 'B' (Table 5).

The Group 'A' pre NDI was $38 \pm 8.77$ and was reduced to $23.67 \pm 4.52$ after treatment. The difference is statistically significant (' $\mathrm{t}$ ' $=10.64,{ }^{\prime} \mathrm{p}$ ' $=0.001$ ). The mean pre NDI for group 'B' was $32.17 \pm 6.33$ and it was reduced to $22.53 \pm 3.99$ after treatment. The 
Table 3. Comparison of cervical extension ROM

\begin{tabular}{|c|c|c|c|c|c|c|c|c|c|c|c|c|}
\hline \multirow{3}{*}{$\begin{array}{l}\text { Cervical ROM } \\
\text { Measurement }\end{array}$} & \multicolumn{4}{|c|}{$\mathbf{A}$} & \multicolumn{4}{|c|}{ B } & \multicolumn{4}{|c|}{ Pre post Difference } \\
\hline & \multicolumn{2}{|c|}{ Pre } & \multicolumn{2}{|c|}{ Post } & \multicolumn{2}{|c|}{ Pre } & \multicolumn{2}{|c|}{ Post } & \multicolumn{2}{|c|}{$\mathbf{A}$} & \multicolumn{2}{|c|}{ B } \\
\hline & Mean & S.D & Mean & S.D & Mean & S.D & Mean & S.D & Mean & S.D & Mean & S.D \\
\hline Cervical Extension in $\mathrm{cm}$ & 16.91 & 0.68 & 18.45 & 0.62 & 16.91 & 1.23 & 17.96 & 0.78 & 1.53 & 0.55 & 1.05 & 0.56 \\
\hline $\begin{array}{l}\text { 't' } \\
\text { 'p' }\end{array}$ & \multicolumn{4}{|c|}{$\begin{array}{l}10.75 \\
0.001\end{array}$} & \multicolumn{4}{|c|}{$\begin{array}{c}7.26 \\
0.001\end{array}$} & \multicolumn{4}{|c|}{$\begin{array}{c}2.36 \\
0.026\end{array}$} \\
\hline
\end{tabular}

Table 4. Comparison of RT cervical rotation ROM

\begin{tabular}{|c|c|c|c|c|c|c|c|c|c|c|c|c|}
\hline \multirow{3}{*}{$\begin{array}{l}\text { Cervical ROM } \\
\text { Measurement }\end{array}$} & \multicolumn{4}{|c|}{ A } & \multicolumn{4}{|c|}{ B } & \multicolumn{4}{|c|}{ Pre post Difference } \\
\hline & \multicolumn{2}{|c|}{ Pre } & \multicolumn{2}{|c|}{ Post } & \multicolumn{2}{|c|}{ Pre } & \multicolumn{2}{|c|}{ Post } & \multicolumn{2}{|c|}{ A } & \multicolumn{2}{|c|}{ B } \\
\hline & Mean & S.D & Mean & S.D & Mean & S.D & Mean & S.D & Mean & S.D & Mean & S.D \\
\hline Cervical RT Rotation in $\mathrm{cm}$ & 14.09 & 1.58 & 13.12 & 0.98 & 13.23 & 0.98 & 12.71 & 0.65 & 0.97 & 0.75 & 0.52 & 0.53 \\
\hline $\begin{array}{l}' \mathrm{t} ' \\
\mathrm{c} \mathrm{p}\end{array}$ & \multicolumn{4}{|c|}{$\begin{array}{c}4.99 \\
0.001\end{array}$} & \multicolumn{4}{|c|}{$\begin{array}{c}3.80 \\
0.002\end{array}$} & \multicolumn{4}{|c|}{$\begin{array}{l}1.89 \\
0.07\end{array}$} \\
\hline
\end{tabular}

Table 5. Comparison of Lt cervical rotation ROM

\begin{tabular}{|c|c|c|c|c|c|c|c|c|c|c|c|c|}
\hline \multirow{3}{*}{$\begin{array}{l}\text { Cervical ROM } \\
\text { Measurement }\end{array}$} & \multicolumn{4}{|c|}{$\mathbf{A}$} & \multicolumn{4}{|c|}{ B } & \multicolumn{4}{|c|}{ Pre post difference } \\
\hline & \multicolumn{2}{|c|}{ Pre } & \multicolumn{2}{|c|}{ Post } & \multicolumn{2}{|c|}{ Pre } & \multicolumn{2}{|c|}{ Post } & \multicolumn{2}{|c|}{ A } & \multicolumn{2}{|c|}{ B } \\
\hline & Mean & S.D & Mean & S.D & Mean & S.D & Mean & S.D & Mean & S.D & Mean & S.D \\
\hline Cervical Left-rotation in $\mathrm{cm}$ & 14.11 & 1.54 & 13.09 & 0.97 & 13.13 & 1.05 & 12.59 & 0.92 & 1.01 & 0.73 & 0.54 & 0.08 \\
\hline $\begin{array}{l}\text { 't' } \\
\text { 'p' }\end{array}$ & & & $\begin{array}{c}33 \\
001\end{array}$ & & & & & & & & & \\
\hline
\end{tabular}

difference is statistically significant (' $\mathrm{t}$ ' $=7.73$, ' $\mathrm{p}$ ' $=$ $0.001)$. The mean difference in improvement in group ' $\mathrm{A}$ ' was $14.33 \pm 5.21$ which is comparatively higher than group ' $\mathrm{B}$ ' which was $9.33 \pm 4.67$. The difference is statistically significant ( $\mathrm{t}$ ' $=2.76$, 'p' $=0.010)$. Hence, NDI improvement was significantly higher in group 'A' (Table 6).

\section{Discussion}

\subsection{The Nature of Study Population}

The gender distribution was equal in both groups. The number of female patients (66.7\%) was higher than that of male patients (33.3\%). Many previous studies report

Table 6. NDI comparison

\begin{tabular}{|c|c|c|c|c|c|c|c|c|c|c|c|c|}
\hline \multirow{3}{*}{ NDI Measurement } & \multicolumn{4}{|c|}{ A } & \multicolumn{4}{|c|}{ B } & \multicolumn{4}{|c|}{ Pre post Difference } \\
\hline & \multicolumn{2}{|c|}{ Pre } & \multicolumn{2}{|c|}{ Post } & \multicolumn{2}{|c|}{ Pre } & \multicolumn{2}{|c|}{ Post } & \multicolumn{2}{|c|}{ A } & \multicolumn{2}{|c|}{ B } \\
\hline & Mean & S.D & Mean & S.D & Mean & S.D & Mean & S.D & Mean & S.D & Mean & S.D \\
\hline NDI & 38 & 8.77 & 23.67 & 4.52 & 32.17 & 6.33 & 22.53 & 3.99 & 14.33 & 5.21 & 9.33 & 4.67 \\
\hline $\begin{array}{l}' \mathrm{t} ' \\
\text { 'p' }\end{array}$ & \multicolumn{4}{|c|}{$\begin{array}{l}10.64 \\
0.001\end{array}$} & \multicolumn{4}{|c|}{$\begin{array}{c}7.73 \\
0.001\end{array}$} & \multicolumn{4}{|c|}{$\begin{array}{c}2.76 \\
0.010\end{array}$} \\
\hline
\end{tabular}


that female patients are the maximum for this cervical condition ${ }^{15,16}$. The age distribution shows that 35 to 40 years was the common age denoted by $53.3 \%$ in group A and $40 \%$ in group B. The present study result of age of occurrence coincides well with the recent studies ${ }^{17,18}$. The majority of the study patient was a manual worker reported by $66.7 \%$ in group 'A' and $33.3 \%$ in the group 'B'. The present study was conducted in a rural region of Chidhambaram where manual labor represents maximal numbers. Repetitive physical work demands and practice of carrying heavy loads on the head to make them vulnerable to undue stress on the joint and surrounding structures that contribute to early wear and tear. The majority of female patients are housewives representing $20 \%$ in group 'A' and $40 \%$ in the group 'B'. Again, physical requirements of the cervical spine placed them at risk of cervical spondylosis. The common duration of condition was reported at $66.7 \%$ in group A and $53.3 \%$ in group B for 1 to 3 months.

\subsection{Interpretation of Improvement in MMT}

It has been hypothesized that MMT can exert its impact by stretching the posterior structures and it could correct the positional fault between the affected facets, thus correcting the biomechanics of the joints. It could release an entrapped meniscoid between the facets joint and assist to increase motion at the desire level ${ }^{8}$.

\subsection{Interpretation of Improvement in IET}

IET may exert the effect by relieving pain associated with the degenerative zygagophyseal joint. Gentle mobilization of these joints can have an analgesic effect by stimulating mechanoreceptor and the mobilizing effect of traction on degenerated spinal joints can help improve the mobility of these joint ${ }^{9}$.

\subsection{Comparison of Improvement of MMT and IET Technique Group-wise Analysis}

For NPRS, the mean difference of improvement in group A was comparatively higher than group $B$. Therefore, the reduction NPRS (Improvement) is significantly higher in group A. Both the statistical results of the group were significant, while the MMT clinically showed an additional pain improvement. Manual traction can reduce the H-reflex, evoking as an inhibitory reaction in the central nervous system and increasing the firing threshold of individual alpha motor neurons resulting in relaxation of the cervical muscles ${ }^{9}$. It might stimulate mechano receptor and proprioceptor in and around the joint. The reason probably the traction force at the desired level (segmental level) prevents force being transmitted to the other level ${ }^{8}$.

For NDI, the mean difference of improvement was comparatively higher in group A than in group B. MMT technique can be used to stretch the muscles and the facet joint capsules and widen the inter vertebral foramen. The angle of pull, head position and placement of force through specific hand placement can be controlled by the therapist ${ }^{8}$. Thus, this approach maximizes the relief of symptoms.

For cervical ROM, the cervical extension and left rotation of both groups were, significantly but right-side rotation is insignificant. While the MMT shows clinically added improvements in cervical extension and left side rotation. The reason is probably the traction force might unlock jammed facet, helps in stretching the posterior structures and open intervertebral foramen, mobilization induced movement help to provide nutrition to the facet joint and disc ${ }^{8}$.

Khan, Ket al, 2016 stated that multimodal approaches combined with cervical traction and core muscle strengthening exercise procedure have more positive results in the management of cervical pain. On the other hand, the finding of their study suggested that manual cervical traction with physical modality was found best and effective in relieving pain and restoring patient's function of activities of daily living with significant improvement in symptoms with excellent patient outcomes ${ }^{19}$.

Kavitha Kiritkumar Bosmia and Jayashree Raju Kotwal, 2015 stated that manual traction pull force is applied directly to the affected spine level. As the traction separates the spinous process, the size of the intervertebral foramina increases and also improves the intervertebral movement at that level. In IET pull is distributed over the entire cervical spine not concentrating on a specific affected region. Thus, IET gives a generalized treatment unlike MT is localized on affected segment ${ }^{20}$.

Some factor with respect to IFT may have accounted for the modest effect size observed for examples, although the stimulation of small diameter fibers has been shown to have a more positive effect for chronic pain compared with stimulation of large diameter fibers (alpha, beta) ${ }^{21}$. The included studies, irrespective of the type of pain used stimulus parameters that were primarily related to 
the stimulation of large diameter fibers, recognize the rapid onset of analgesia and its short analgesic effect is important $\mathrm{t}^{22}$. It is therefore plausible that in chronic pain, which a dominant condition in this evaluation was. Under these stimulation parameters, the efficacy of IFT has been attenuated, resulting in a small effect in reported pain reduction.

Strengthening and endurance training such as isometric neck exercise may have been reduced neck pain and improved cervical ROM because improvements in cervical extensor and strength of cervical flexors improve the neck posture and bring the center of gravity in its place correcting biomechanics of the spine. Cochrane review states that strengthening and endurance exercise improves the activation of deep cervical flexors and extensor muscle that are effective in improving cervical ROM. Exercise improves blood circulation and oxygenation that reduce spasm and stiffness increasing the $\mathrm{ROM}^{23}$. Exercise training involves performing and holding inner range position of cranio cervical flexors, the anatomical action of deep cervical flexor muscle. Suggested ${ }^{24}$ proprioceptive and neck strengthening exercise reduces neck pain.

\subsection{Limitations and Future Direction}

- The studied sample size is significantly smaller. In order to further validate this therapeutic technique for cervical spondylosis, it may be essential to increase the number of participants.

- The present study focused only on cervical extension and rotation. Further studies can be done by including all possible neck ROM.

\subsection{Strength of the Study}

- IET is the conventional method of treatment, whereas MMT is the recent advancement in the treatment of cervical spondylosis.

- The MMT provides comfort for the patient as it is performed manually considering the performance of the patient. It enables the clinician to feel the reaction of the patient to the treatment.

- Mulligan belt assisted therapy provides less energy expenditure to the therapist and electricity is not needed for MMT treatment.

\section{Conclusion}

The result of the study concluded that manual Mulligan traction and intermittent electrical traction are effective in reducing pain, improving cervical range of motion and functional performance in cervical spondylosis. However, the subject who received the manual Mulligan traction with IFT and isometric neck exercise showed better improvement in reducing pain, improving cervical range of motion and functional performance than subject who received the intermittent electrical traction.

\section{References}

1. Cote P, Cassidy JD, Carroll LJ, Kristman V. The annual incidence and course of neck pain in the general population: a population-based cohort study. Pain. 2004; 112(3): 267-73. https://doi.org/10.1016/j.pain.2004.09.004. PMid: 15561381.

2. Hassan Al-Shatoury HA, Galhom AA, Hommer DH (Chief Ed.). Cervical spondylosis. 2005.

3. Konstantinovic LM, Cutovic MR, Milovanovic AN, Jovic SJ, Dragin AS, Letic MD et al. Low-level laser therapy for acute neck pain with radiculopathy. a double-blind, placebo-controlled randomized study. Wiley Periodicals, Inc. Pain Medicine. 2010; 11:1169-78. https://doi.org/10.1111/ j.1526-4637.2010.00907.x. PMid: 20704667.

4. Bergmann TF, Peterson DH. Chiropractic Technique, Principles and Procedures. Third edition: Copyright. 2011, 2002, 1993 by Mosby. P. 155-85.

5. René Fejer, Kirsten Ohm Kyvik, Jan Hartvigsen. The prevalence of neck pain in the world population: A systematic critical review of the literature. Eur Spine J. 2006; 15(6):834-48. https://doi.org/10.1007/s00586-004-0864-4. PMid: 15999284, PMCid: PMC3489448.

6. Van der Heijden GJ, Beurskens AJ, Koes BW, Assendelft WJ, de Vet HC, Bouter LM. The efficacy of traction for back and neck pain: A systematic, blinded review of randomized clinical trial methods. Phys. Ther. 1995; 75(2): 93-104. https://doi.org/10.1093/ptj/75.2.93. PMid: 7846138.

7. Cleland JA, Childs JD, McRae M, Palmer JA, Stowell T. Immediate effects of thoracic manipulation in patients with neck pain: A randomized clinical trial. Man Ther. 2005; 10(2):127-35. https://doi.org/10.1016/j.math.2004.08.005. PMid: 15922233.

8. Deepak Kumar. Manual Mulligan concept: International Edition Paperback. Capri institute of manual therapy; 2nd ed; 2015. p. 19-20.

9. Susan L Michlovitz, Thomas P Nolan Jr. Modalities for Therapeutic Intervention (Contemporary Perspectives 
in Rehabilitation), Kindle Edition;Publisher: F.A. Davis Company; 4 ed, 2005. p.165-71.

10. Browder DA, Erhard RE, Piva SR. Intermittent cervical traction and thoracic manipulation in the management of mild cervical compressive myelopathy attributed to cervical herniated disc: A case series. J Orthop Sports Phys Ther. 2004; 34(11):701-12. https://doi.org/10.2519/ jospt.2004.34.11.701. PMid: 15609490.

11. Reilly JP, Gersten JW, Clinkingbeard JR. Effect of pelvicfemoral position on vertebral separation produced by lumbar traction. Phys Ther. 1979; 59(3):282-86. https://doi. org/10.1093/ptj/59.3.282. PMid: 419172.

12. Jensen MP, Karoly $\mathrm{P}$, Braver S. The measurement of clinical pain intensity: A comparison of six methods. Pain. 1986; 27(1):117-26. https://doi.org/10.1016/03043959(86)90228-9.

13. Norkin, Cynthia C, White D Joyce. Measurement of joint motion: A guide to goniometry, Philadelphia: F.A. Davis; 3rd ed: 1995. p. 310-26.

14. Vernon HT, Mior SA. The neck disability index: A study of reliability and validity. J Manip Physiol Ther. 1991; 14:40915. https://doi.org/10.1037/t35122-000.

15. Jari Ylinen, Esa-Pekka Takala,Matti Nykänen, Arja Häkkinen, Timo Pohjolainen, Sirkka-Liisa Karppi et al. Active neck muscle training in the treatment of chronic neck pain in women-A randomized controlled trial. JAMA. 2003; 289(19):2509-16. https://doi.org/10.1001/ jama.289.19.2509. PMid: 12759322.

16. Anna MacDowall, Yohan Robinson, Martin Skeppholm, Claes Olerud. Anxiety and depression affect pain drawings in cervical degenerative disc diseas. Ups J Med Sci. 2017; 122(2):99-107. https://doi.org/10.1080/03009734.2017.131 9441. PMid: 28503982, PMCid: PMC5441379.

17. RoseBist PK, Anil Kumar Peethambaran ,Gowri Anil Peethambar. Cervical spondylosis: Analysis of clinical and radiological correlation. International Surgery Journal.
2018; 5(2):491-95. https://doi.org/10.18203/2349-2902. isj20180338.

18. Brown G, Park K, Bicknell RT. Management of Occupational shoulder injuries in primary care. J Musculoskelet Disord Treat.2005; 1:002.https://doi.org/10.23937/2572-3243.1510 002.

19. Khan K, Yasmeen S, Ishaque F, Imdad F, Lal W, Sheikh $S$, et al. Effectiveness of manual traction and other physiotherapy treatment in the management of painful cervical radiculopathy. International Journal of Physiotherapy. 2016; 3(3):286-90. https://doi.org/10.15621/ijphy/2016/ v3i3/100829.

20. Kavitha Kiritkumar Bosmia, Jayashree Raju Kotwal. Comparison between the effectiveness of Manual Mulligan traction and intermittent electric traction in cervical spondylosis. Journal of Nursing and Health Science. 2015; 4(5):59-64.

21. Defrin R, Ariel E, Peretz C. Segmental noxious versus innocuous electrical stimulation for chronic pain relief and the effect of fading sensation during treatment. Pain. 2005; 115(1-2):152-60. https://doi.org/10.1016/j. pain.2005.02.018. PMid: 15836978.

22. Sato A, Schmidt RF. Somatosympathetic reflexes: Afferent fibers, central pathways, discharge characteristics. Physiol Rev. 1973; 53(4):916-47. https://doi.org/10.1152/physrev.1973.53.4.916. PMid: 4355517.

23. Gross AR, Paquin JP, Dupont G, Blanchette S, Lalonde P, Cristie T, et al. Exercises for mechanical neck disorders: A Cochrane review update. Man Ther. 2016; 24:25-45. https:// doi.org/10.1016/j.math.2016.04.005. PMid: 27317503.

24. Dusunceli Y, Ozturk C, Atamaz F, Hepguler S, Durmaz B. Efficacy of neck stabilization exercises for neck pain: A randomized controlled study. Rehabil Med. 2009; 41(8):626-31. https://doi.org/10.2340/16501977-0392. PMid: 19565156. 